\title{
Smile Makeover with Porcelain Laminate Veneer: A Case Report
}

\author{
Nikita Sarraf ${ }^{1}$, Anubha Sejra ${ }^{2}$, Deepak Raisingani ${ }^{3}$, Ashwini B Prasad ${ }^{4}$, Harshit Srivastava $^{5}$, Prachi Mital ${ }^{6}$
}

\begin{abstract}
One of the principle topics for contemporary dentistry is to re-establish patient lost dental esthetic appearance.

To re-establish patient's lost dental esthetic appearance is one of the most important topics for contemporary dentistry. New treatment materials and methods have been discovered and introduced in market in order to gain this aim. Conservative and esthetic approaches, such as direct and indirect laminate veneer restorations, instead of full-ceramic crowns for anterior are preferred by most Dentist's where esthetics is really important.

To correct existing abnormalities, esthetic deficiencies and discolorations, laminate veneers are used. They are processed in two different ways: direct or indirect. Direct laminate veneers are based on the principle of application of a composite material directly to the prepared tooth surface in the dental clinic. Indirect laminate veneers may be produced from composite materials or porcelain, which are cemented to the tooth with an adhesive resin. In this case report Indirect ceramic laminate veneers were used to enhance the esthetic appearance of the young patient. Keywords: Composite, Discoloration, Indirect restoration, Esthetics

Journal of Mahatma Gandhi University of Medical Sciences and Technology (2018): 10.5005/jp-journals-10057-0066
\end{abstract}

\section{INTRODUCTION}

Smile, a person's ability to express a range of emotions with the structure and movement of the teeth and lips, can often determine how well a person can function in society. ' Of course, the importance given to a beautiful smile is not new. The search for beauty can be traced to the earliest civilizations; both the Phoenicians (app 800 BC) and Etruscians (app 900 BC) carefully carved animal tusks to simulate the shape, form and hue of natural teeth. It was not until the 18th century that dentistry was recognized as a separate discipline and its various branches were established. ${ }^{2}$ Pierre Fauchard (1678-1761) of France, the leader of the movement, together with several colleagues modernized and promoted dentistry and also advocated esthetic practices. ${ }^{3}$

Treatment of unesthetic anterior teeth is steadily growing. There are several treatment options which are proposed according to restoration of the esthetic appearance of the dentition. For many years, the most predictable and durable esthetic correction of anterior teeth has been achieved by the full crowns. But full crowns lead to more removal of tooth structure therefore now more conservative options are available to mask tooth discoloration. To correct unesthetic tooth forms there are veneers, which can be of composite as well as porcelain. ${ }^{4,5}$ But major limitations with composite veneers include short lifespan, Susceptibility to discoloration, Wear and Marginal Fracture thus reducing long term esthetics results therefore to overcome these limitations porcelain veneers are used ${ }^{6}$.

The idea of porcelain veneers is not a new one. In 1938, Dr. Charles Pincus ${ }^{7}$ described a technique in which porcelain veneers were retained by a denture adhesive during cinematic filming. Simonsen-Calamia ${ }^{8}$ and Horn $^{9}$ reinitiated the interest in porcelain veneers by introducing special acid- etching procedures that substantially improved the long term porcelain veneer retention. They demonstrated that the bond strength of a hydrofluoric acid-etched and silanated veneer to the luting resin composite is
${ }^{1}$ Ex Post Graduate, ${ }^{2}$ Resident, ${ }^{3}$ Vice Principal, Professor and Head, ${ }^{4}$ Associate Professor, ${ }^{5}$ Reader, ${ }^{6}$ Senior Lecturer

${ }^{1-6}$ Department of Conservative Dentistry and Endodontics, Mahatma Gandhi Dental College and Hospital, Jaipur, Rajasthan, India

Corresponding Author: Anubha Sejra, Resident, Department of Conservative Dentistry and Endodontics, Mahatma Gandhi Dental College and Hospital, Jaipur, Rajasthan, India, Phone: 8764252467, e-mail: anubhasejra@gmail.com

How to cite this article: Sarraf N, Sejra A, Raisingani D, Prasad AB, Srivastava H, Mital P. Smile Makeover with Porcelain Laminate Veneer: A Case Report. J Mahatma Gandhi Univ Med Sci Tech 2018;3(1):38-40. Source of support: Nil

Conflict of interest: None

routinely greater than the bond strength of the same luting resin to the etched enamel surface. ${ }^{9}$

\section{Case Description}

A 24-year-old male patient reported to the Department of Conservative Dentistry and Endodontics with a chief complaint of discoloration and wear of previous restoration in upper front teeth (Fig. 1). Patient gave a history of getting a composite veneer in upper anterior teeth 6 month back and patient is dissatisfied through the results. A thorough visual assessment was performed to evaluate the occlusion, morphologic, and optical characteristics were analyzed. The medical history was not significant.

On clinical examination it was found that patient had composite veneer placed in upper front teeth which were discolored and darker than adjacent teeth. Following a detailed clinical examination and careful evaluation of the objective parameters of the patient's smile it was found that ceramic veneers were best suited for the condition in maxillary anterior teeth as they provide the advantage of preservation of most of the natural tooth structure while achieving the esthetics.

(c) The Author(s). 2018Open Access This article is distributed under the terms of the Creative Commons Attribution 4.0 International License (https://creativecommons. org/licenses/by-nc/4.0/), which permits unrestricted use, distribution, and non-commercial reproduction in any medium, provided you give appropriate credit to the original author(s) and the source, provide a link to the Creative Commons license, and indicate if changes were made. The Creative Commons Public Domain Dedication waiver (http://creativecommons.org/publicdomain/zero/1.0/) applies to the data made available in this article, unless otherwise stated. 


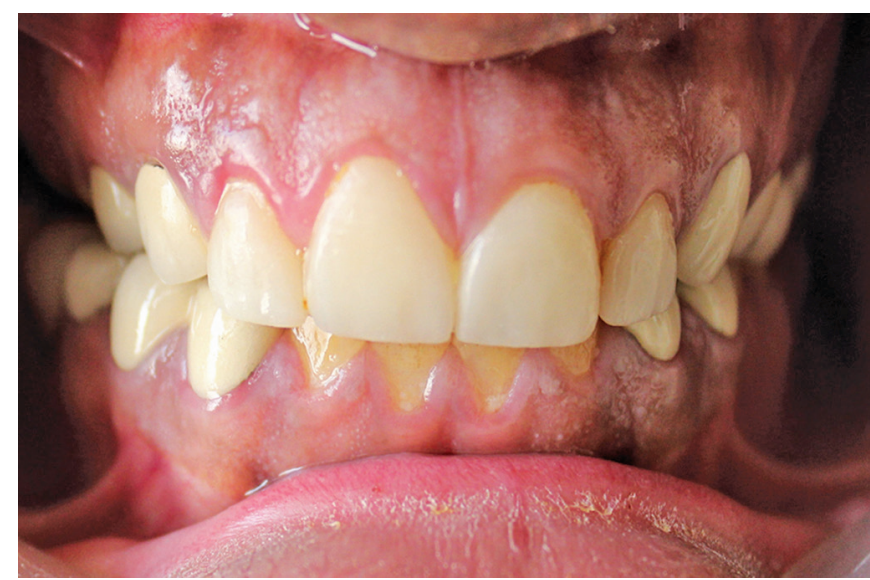

Fig. 1: Preoperative

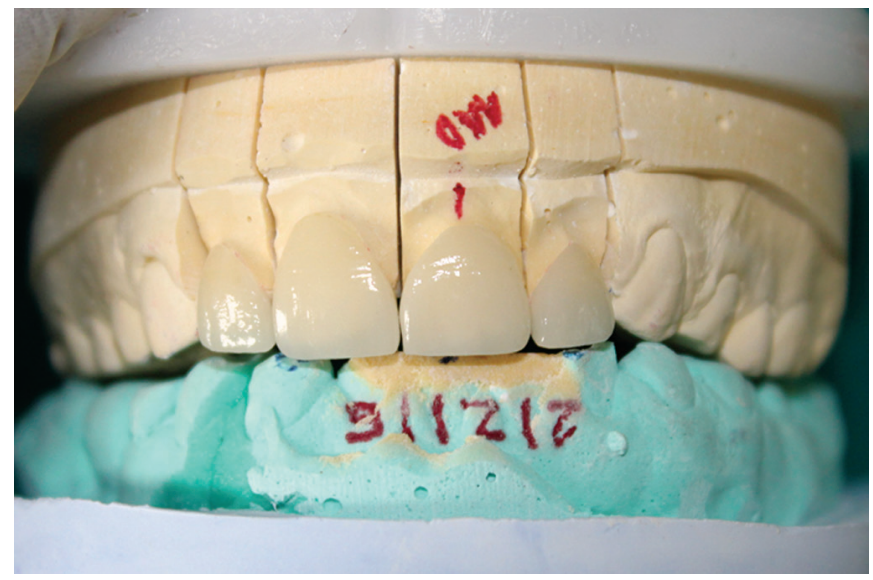

Fig. 3: Try-in on cast

Prior to beginning of teeth preparation, the shade selection was done using vita shade guide and incisal guidance was checked. Rubber dam was placed and tooth reduction for maxillary anterior veneers began by using a $0.5 \mathrm{~mm}$ depth cutting bur on the labial wall, starting from the gingival level moving towards the incisal edge. The lingual margin was placed above the contact point. Dual convergence was given on the labial surfaces to preserve the anatomical form of the labial surface. A long tapered chamfer ended diamond bur was used to reduce the buccal wall to create definite gingival and interproximal finishing line angles. The chamfer was taken slightly into the interproximal areas so as to allow the veneers to cover all the visible aspects of the teeth (Fig. 2).

After completion of the teeth preparation full arch impressions were taken with an addition silicone impressions material (Aquasil, DENTSPLY SIRONA, USA) and an occusal registration was made.

The impression was sent to the lab along with the instructions regarding the underlying final shades, the desired length, width and position of the frontal teeth. At the dental laboratory, refractory stone models of the prepared teeth were made and EMax veneers were fabricated. Veneers were inspected in the dental office prior to the final placement in the patient's mouth for fit, marginal adaptation, appearance, translucency, shade and the absence of the black triangle in the gingival area. The try-in was done (Fig. 3). Each veneer is individually fitted and checked for marginal accuracy.

For final placement was done after rubber dam and retraction cord were placed to maintain a contamination free and dry

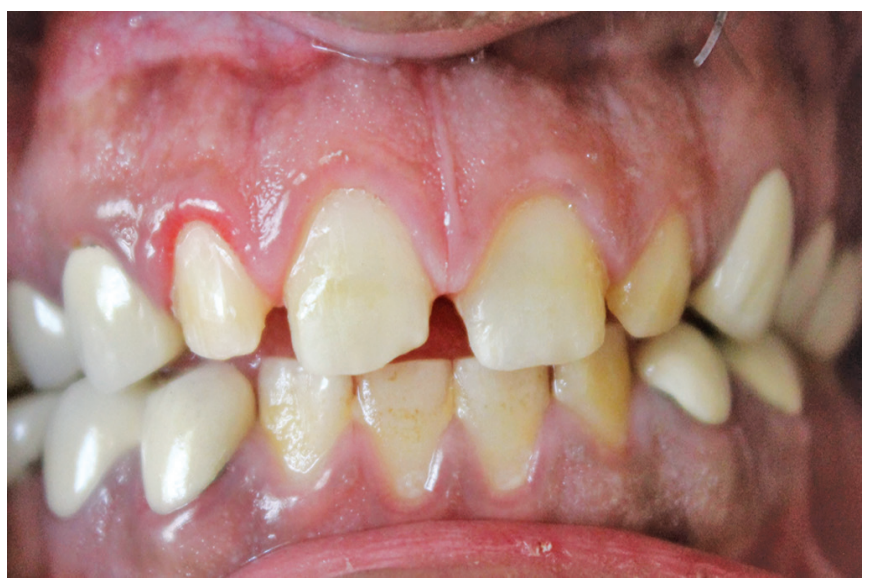

Fig. 2: Tooth preparation

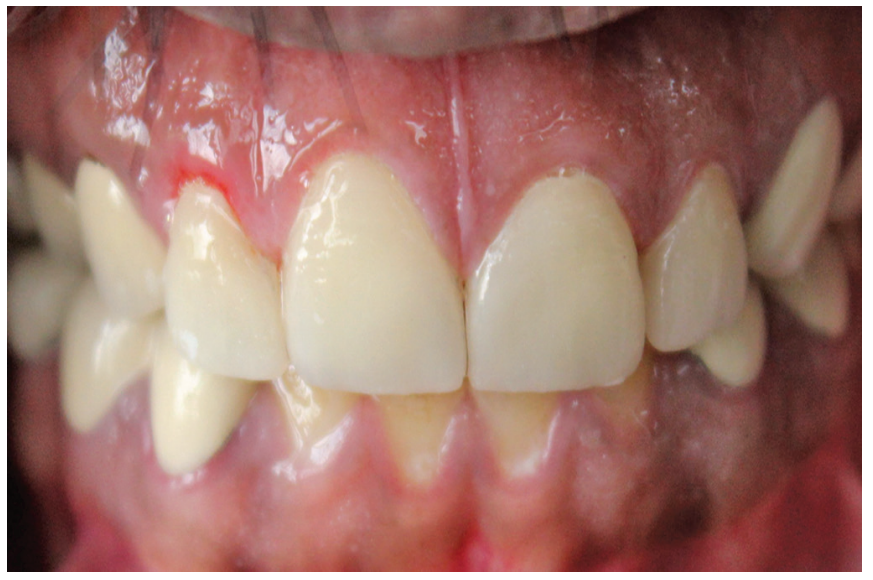

Fig. 4: Veneer cementation

operating field. The teeth for veneers were then pumiced and rinsed. Then, enamel surfaces of the prepared teeth were etched using 37\% phosphoric acid (Etching Gel, Kerr, USA) for 15 seconds followed by thorough rinsing with water spray for 20 seconds and keeping them moist slightly. One-bottle bonding agent (Adper Single Bond, 3M ESPE, USA) was applied in two layers on the etched teeth surfaces using a applicator brush and polymerized with a light-curing unit (Demi LED Light Curing System, 450 nm, Kerr, USA) for 20 seconds. After etching and using silane on the interior surface of the porcelain laminate they were cemented using resin cement (maxcem elite kerr, USA) .The veneers is gently pressed to place, and held there with a gloved finger while polymerizing with the light for 5 to 8 seconds (Fig. 4). The initial excess cement is removed with the probe. Laminate is then completely cured for 20 seconds each on incisal, buccal, palatal aspects. Followed by 6 month follow-up (Fig. 5).

\section{Discussion}

Laminate veneer restoration is the most preferred treatment method for anterior teeth to improve esthetic appearance. Proper Diagnosis and Treatment planning is very important to make the decision for the condition in which the direct, indirect composite resin and indirect ceramic laminate veneers are chosen for the success of the treatment. The dentist has to make the decision after a complete review and a correct indication after proper 


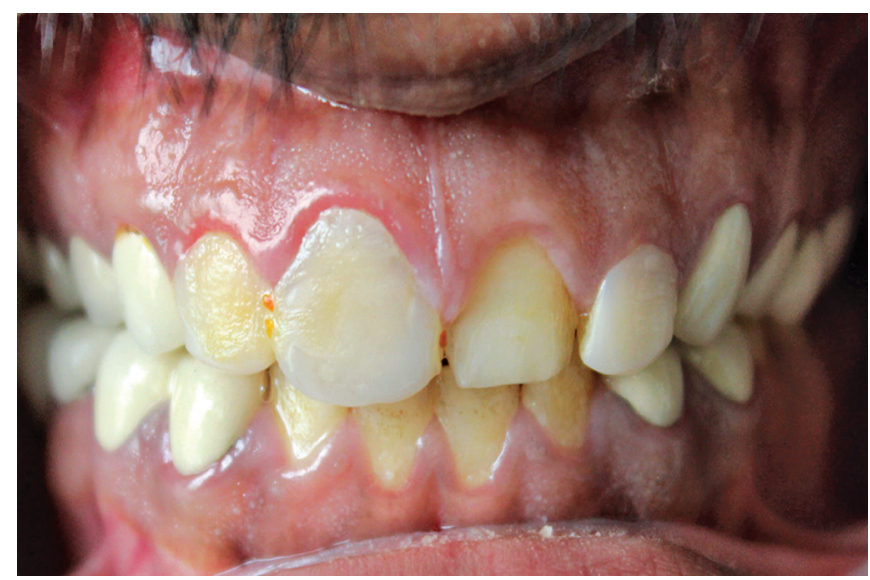

Fig. 5: Six months follow-up

clinical examination. The dentist should also analyze the patient's socioeconomic status, esthetic expenses also. ${ }^{10}$

In this case report presented current evidence suggesting that all-ceramic restorations have an acceptable clinical longevity that accompanies their long-lasting esthetic advantages. Evidence from many clinical studies suggests that clinicians may choose from any all-ceramic system on the basis of patients' esthetic needs for veneers, intracoronal restorations and full-coverage restorations for single-rooted anterior teeth. Additional clinical factors such as adequate preparation depth and cementation can outweigh materials considerations. ${ }^{11}$

Tooth veneering is a minimally invasive procedure that enables the practitioner to apply biomimetic materials in cosmetic dentistry, finding a balance between ceramic and enamel. The great majority of restorative procedures violate the balance between enamel and dentin in natural teeth. Unlike these procedures, the use of porcelain laminate veneers offers an excellent combination of hardness, resistance, and resilience. ${ }^{12}$ According with Magne and Belser, a tooth restored with a porcelain laminate veneer that is subjected to posterior-anterior force recovers 89 to $96 \%$ of its coronary stiffness when compared with a healthy tooth. ${ }^{13}$

Diagnostic wax- mock-up techniques are great tools during clinical evaluation and treatment planning, as they provide information on the possibility of using porcelain laminate veneers with minimal or no dental wear. ${ }^{14}$ Establishing a treatment plan using diagnostic wax-ups is utterly necessary to determine the exact final position and anatomy of the veneer. ${ }^{15}$

EMax porcelain veneers were used, they are a type of all-ceramic dental restorations which is preferred for its longer lasting aesthetic qualities. It has an appealing translucent color and have a natural life-like appearance. But it may fracture due to inadequate material thickness. ${ }^{16}$

Clinical factors such as remnant/substrate color, laminate thickness and luting system are known to potentially interfere with the final esthetic result. That said, the professional may resort to clinical interventions prior to optimizing esthetic results, as well as promote the use of minimally invasive or conservative techniques.

\section{Conclusion}

As with most dental treatment, there should not be a "one size fits all" philosophy for veneers. Clinicians need to consider all esthetics options when treatment planning. A thorough clinical examination with esthetic evaluation is important for achieving an acceptable final result.

\section{References}

1. Bloom DR, Padayachy JN. Increasing occusal vertical dimension Why, When, How. Br Dent J. 2006;200:251-256

2. Nakabayashi N, Kojima K, Masuhara E. The promotion of adhesion by infiltration of monomers into tooth substrates. Journal of Biomedical Materials Research 1982;16:265-273.

3. Van Meerbeek B, Vanherle G, Lambrechts P, et al. Dentin- and enamelbonding agents. Current Opinion in Dentistry 1992;2:117-127.

4. Pashley DH, Ciucchi B, Sano H, et al. Permeability of dentin to adhesive agents. Quintessence International 1993;24:618-631.

5. Peumans M, Van Meerbeek B, Lambrechts P, et al. The five-year clinical performance of direct composite additions to correct tooth form and position. Part I: aesthetic qualities. Clinical Oral Investigations 1997; 1:12-18.

6. Peumans M, Van Meerbeek B, Lambrechts P, et al. The five-year clinical performance of direct composite additions to correct tooth form and position. Part II: marginal qualities. Clinical Oral Investigations 1997;1:19-26.

7. Pincus CR. Building mouth personality. Journal of South California Dental Association 1938;14:125-129.

8. Simonsen RJ, Calamia JR. Tensile bond strength of etched porcelain. Journal of Dental Research 1983;62:297 Abstract 1154.

9. Horn RH. Porcelain laminate veneers bonded to etched enamel. Dental Clinics of North America 1983;27:671-684.

10. Calamia JR, Simonsen RJ. Effect of coupling agents on bond strength of etched porcelain. Journal of Dental Research 1984;63:179 Abstract 79.

11. Ozdemir E, Agüloğlu S, Değer Y. Ön dişlerinde mine defek-tleri bulunan üç hastanın kompozit ve porselen laminate ve-neerler kullanılarak estetik rehabili asyonu (olgu raporu). GÜ Dişhek Fak Der 2009;26:171-176

12. Porcelain veneers: a review of the literature M. Peumans*,

13. B. Van Meerbeek, P. Lambrechts, G. Journal of Operative Dentistry September 1999.

14. Magne P, Belser U. Estética dental natural. Restaurações adesivas de porcelana na dentição anterior: uma abordagem biomimética. São Paulo: Santos; 2003.

15. Magne $P$, Douglas WH. Additive contour of porcelain veneers: a key element in enamel preservation adhesion, and esthetics for aging dentition. J Adhes Dent. 1999;1(1):81-92

16. T. Dolidze, I. Bitarova. Advantages and disadvantages of E-Max and Zirconia Crowns. EU Journal . 2016; 465-460. 